\title{
Dual Output DC-DC converter Based on CUK and SEPIC
}

\author{
Shankara Pai B $\mathbf{B}^{\mathbf{1}}$, Prof. K Vasudeva Shettigar ${ }^{2}$ \\ Student, Department of Electrical and Electronics Engineering, NMAM Institute of Technology, Udupi, India ${ }^{1}$ \\ Associate Professor, Department of Electrical and Electronics Engineering, NMAM Institute of Technology, Udupi, \\ India $^{2}$
}

\begin{abstract}
The proposed model of dual output converter is presented based on CUK and SEPIC converters. The dual output of a single input voltage source is useful in various applications, like DC micro grids, Electrical machines, Solar Energy systems. The proposed converter requires less number of inductor and capacitor as it is compared with the separate converter. The proposed converter is useful regarding the different output polarities. In addition, this converter can be used as multiple voltages power supply. The converters analysis is carried out in continuous current mode. The proposed converter is simulated both in open loop and closed loop using MATLAB/SIMULINK model.
\end{abstract}

Keywords: Dual output, CUK and SEPIC converter, DC Micro grid.

\section{INTRODUCTION}

In recent days, use of renewable energy such as innovative topology with stepping up and down ability is photovoltaic, wind energy, ocean wave, and fuel cell are presented in [6]. In this topology, the output voltage is more popular. Applying DC-DC converters in these types promoted by means of clamp diodes. So each of the output of applications necessary. Therefore, presenting new DC- voltage levels is less and outputs depend on loads DC converter topologies with some advantages such as proportion. In [7] a dual input single output is introduced high voltage gain and reliability are more important. This which is extracted from traditional boost and buck-boost converter can be applied in multi-voltage DC grid to feed converters. This converter has better voltage gain rather different applications [1]. Furthermore, multi-level voltage than the previously mentioned converters. According to is needed in the electrical machine for battery charging the extension of SEPIC converter, another converter is and motor drive. Although this topology uses the obtained in [8] that has remarkable voltage gain. In this transformer, it is non-isolated. Besides output magnitudes topology firstly the SEPIC converter gain exchange to the are equal, as the result, they are not controllable traditional boost converter, then it has multiplied to $n$ separately. The voltage gains improved by using the factor. To implement this theory in the first case single transformer. On the other hand, using transformer leads to diode and a capacitor has added to SEPIC circuit then the cost and volume increment. In [2] a dual output some diodes, capacitors, inductors and switches added to converter is introduced by combining a SEPIC and a the circuit to multiple the voltage gain. The addition of the multilevel boost converter with high voltage, but output number of elements in this converter reduces the reliability voltage level is not independent in this converter too. In of this topology. In addition, this converter has single addition, the number of the element increases output although it uses bulk capacitors. In this paper, a proportionally to voltage gain improvement. For example, dual output converter is introduced using traditional if the boost converter gain promotes five times it has to SEPIC and CUK converters. In this topology, there are use 4 pairs of diodes and capacitors. In [3] a dual output two diodes and two synchronous switches. As this converter is introduced based on the SEPIC and traditional converter is designated based on the CUK and SEPIC buck-boost converter. A multi-output boost converter with converters, it has both topology advantages such as diode clamp topology is presented in [4]. The output continuous current.

voltage is divided between different outputs using diode clamp topology in this converter. Therefore, output voltage depends on the load. This dependence leads to some limitation for obtaining different voltages. In [5] a family of the multi-output DC-DC converter is introduced. Most of the proposed topology of this family use active switches to divide voltage to the different outputs. An

\section{PROPOSED SYSTEM}

The conventional topology of CUK and SEPIC converters shown in Fig.1. and Fig.2. An innovative topology is obtained of these two converters shown in Fig.3. This topology can give two voltages with different polarity and 
National Conference on Advances in Electrical Engineering

NMAM Institute of Technology, Nitte

Vol. 5, Special Issue 2, April 2017

different level. Also, output voltages are controlled using Durin ON time of gating pulses. Both the switches $\mathrm{S}$ and converter switches. In this topology, Q1 and Q2 switches S1 are turned ON. During now, both the diodes are turned operate synchronously. According to the circuit structure,

diode D1 and D2 operate complementarily.

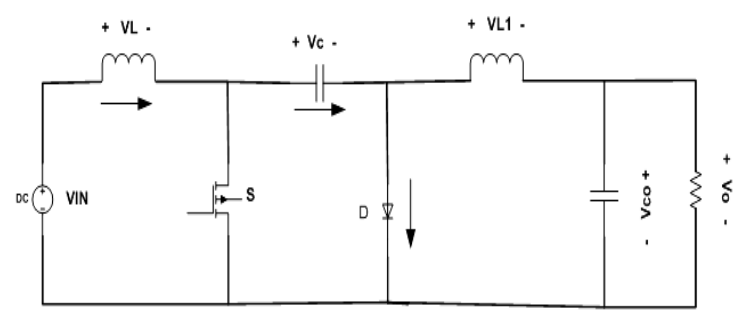

Fig.1.CUK converter

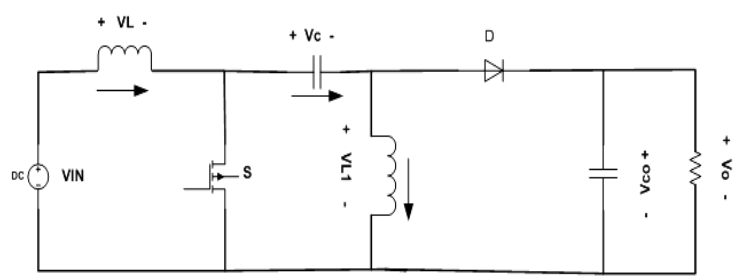

Fig.2. SEPIC converter

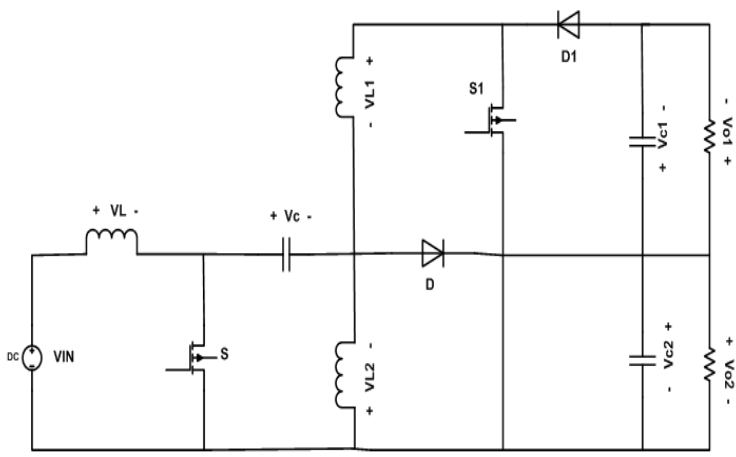

Fig.3.Proposed Dual output SEPIC-CUK converter

A. OPERATION MODE1 $(0<\mathrm{T}<\mathrm{DT})$

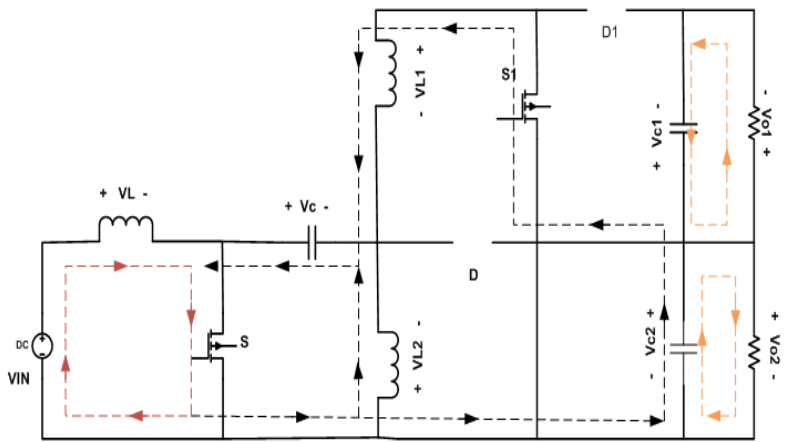

Fig.4.Operating mode when both switches are closed
OFF due to reverse blocking state. doted lines explain the power path. In this mode L, L1, and L2 charges and capacitors $\mathrm{C}, \mathrm{C} 1$ and $\mathrm{C} 2$ are discharges. The circuit equation are as follows,

$$
\begin{aligned}
& V_{I N}=V_{I N} \ldots \ldots \ldots \ldots \\
& I_{C}=-I_{L 1}-I_{L 2} \cdots \\
& V_{L 1}=V_{C}+V_{02} \cdots \cdots \\
& I_{C 1}=-\frac{\text { V0 } 1}{R 1} \cdots \cdots \cdots \\
& V_{L 2}=V_{C} \cdots \cdots \cdots \cdots \\
& I_{C 2}=-\frac{\text { VO2 }}{R 2}-I_{L 1}
\end{aligned}
$$

B. Operation mode2 (when DT<t<T):

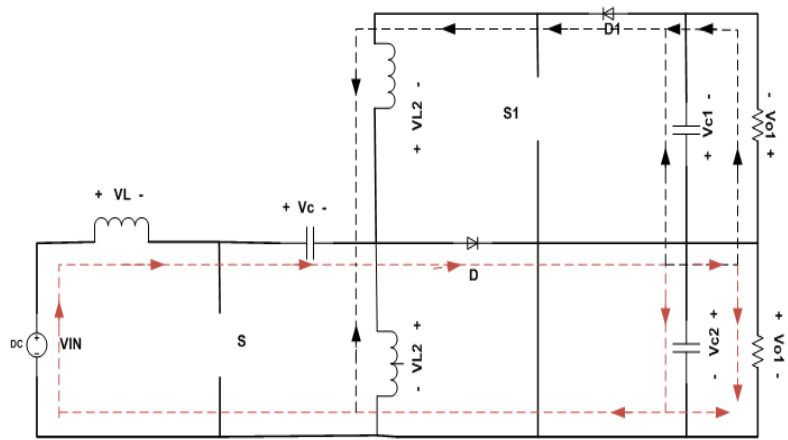

Fig.5. Operating mode when both switches are open

During off period of gate pulse, both the switches S, S1 are turned OFF and Diodes D, D1 are in conducting mode. In this mode inductors L, L1 and L2 are discharges and capacitors $\mathrm{C}, \mathrm{C} 1$ and $\mathrm{C} 2$ are in charging mode. The circuit equations are as follows.

$$
\begin{gathered}
V_{L}=V_{I N}-V_{C}-V_{O 2} \\
I_{C}=-I_{L} \\
V_{L 1}=V_{O 1} \ldots \ldots \ldots \ldots \ldots \ldots \ldots \ldots \ldots \ldots \ldots \ldots \ldots \ldots \ldots \ldots \ldots \ldots \ldots \ldots \\
I_{C 1}=-I_{L 1}-\frac{V O 1}{R 1} \\
V_{L 2}=-V_{O 2} \\
I_{C 2}=I_{L}+I_{L 2}-\frac{V O 2}{R 2}
\end{gathered}
$$

Steady state analysis is done considering all the components are ideal, continuous inductor current. We know that average voltage of an inductor in a period equals zero and average current of a capacitor over a period is zero. $\mathrm{T}$ denotes time period and $\mathrm{D}$ denotes duty cycle. Equations under steady state are,

$$
\begin{aligned}
& V_{I N}-V_{C}-V_{O 2}+D V_{C}+D V_{O 2}=0 \\
& V_{O 1}-D V_{O 1}+D V_{C}+D V_{O 2}=0 \\
& -V_{O 2}+D V_{C}+D V_{O 2}=0 \text {. } \\
& I_{L}-D I_{L 1}-D I_{L 2}-D I_{L}
\end{aligned}
$$




$$
\begin{gathered}
-I_{L 1}-\frac{V 01}{R 1}+D I_{L 1}=0 \ldots \ldots \ldots \ldots \ldots \ldots \ldots \ldots \ldots \ldots \ldots \\
I_{L 2}+I_{L}-\frac{V O 2}{R_{2}}-D I_{L 1}-D I_{L 2}-D I_{L}=0 . .
\end{gathered}
$$

DC equations after simplification are as follows,

$$
\begin{aligned}
& V_{C}=V_{I N} \ldots \ldots \ldots \\
& V_{O 1}=-\frac{D * V_{I N}}{(1-D)^{2}} \\
& V_{O 2}=\frac{D * V_{I N}}{(1-D)} \ldots \ldots
\end{aligned}
$$

\section{SIMULATION RESULTS}

The proposed converter is modelled in MATLAB/SIMULINK. The model is simulated with the parameter as shown in Table .1. The SIMULINK model of the converter with open loop is shown in Fig.6

Tabe.1. Designed values

\begin{tabular}{|c|c|c|}
\hline Sl. No. & Element & Values \\
\hline 1 & Switching frequency & $20 \mathrm{KHz}$ \\
\hline 2 & Duty cycle D & 0.7 \\
\hline 3 & Supply voltage & $30 \mathrm{~V}$ \\
\hline 4 & Inductor $\mathrm{L}$ & $150 \mathrm{uH}$ \\
\hline 5 & Inductor $\mathrm{L}_{1}$ & $1 \mathrm{mH}$ \\
\hline 6 & Inductor $\mathrm{L}_{2}$ & $1 \mathrm{mH}$ \\
\hline 7 & Capacitor $\mathrm{C}$ & $220 \mathrm{uF}$ \\
\hline 8 & Capacitor $\mathrm{C}_{1}$ & $4700 \mathrm{uF}$ \\
\hline 9 & Capacitor $\mathrm{C}_{2}$ & $4700 \mathrm{uF}$ \\
\hline 10 & Resistor $\mathrm{R}_{1}$ & $230 \Omega$ \\
\hline 11 & Resistor $\mathrm{R}_{2}$ & $70 \Omega$ \\
\hline
\end{tabular}

The converter is modelled in MATLAB/SIMULINK environment. For simulation of proposed converter, the input is taken as $30 \mathrm{~V}$. Table shows the designed values of inductor, capacitor and switching frequency. The switch used here is MOS-FET.

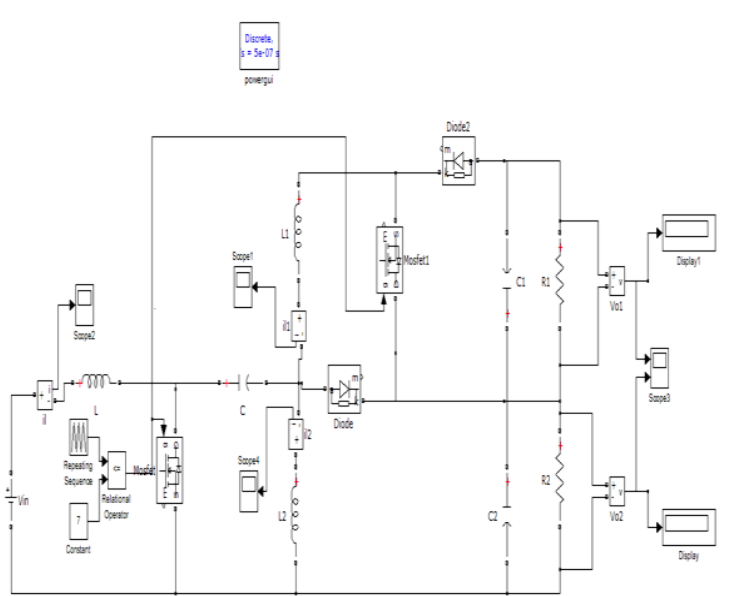

Fig.6. Simulation model of proposed converter without feedback
The switching is done by comparing saw tooth waveforms with a control signal. If the control signal is higher than the repetitive waveform, then signal turns high.

From the simulation result, it can be observed that the CUK converter output is approximately $-230 \mathrm{~V}$. It can be observed that, from the simulation result SEPIC converter output is approximately $70 \mathrm{~V}$.

The Inductor current $I_{L}$ is equal to the source current, when the switches are closed. From the simulation result, as shown in fig.9,10,11. the inductor current $\mathrm{I}_{\mathrm{L}}$ is found to be $10 \mathrm{~A}$ and inductor currents $\mathrm{I}_{\mathrm{L} 1}$ and $\mathrm{I}_{\mathrm{L} 2}$ are found to be 5.7 and $1.6 \mathrm{~A}$ respectively.

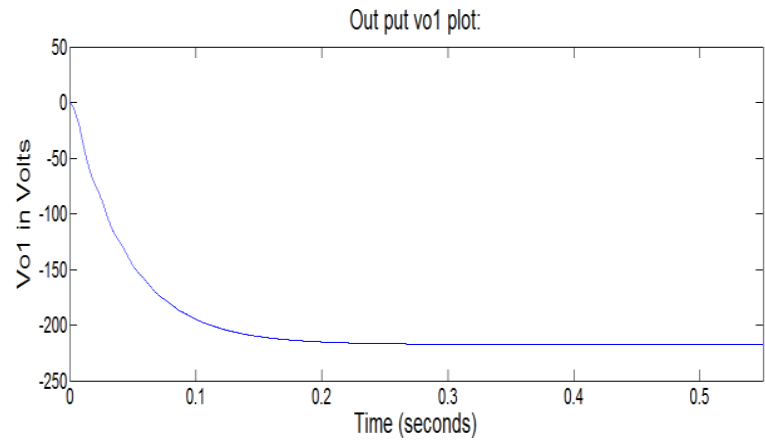

Fig.7. Output voltage $\mathrm{V}_{\mathrm{o} 1}$

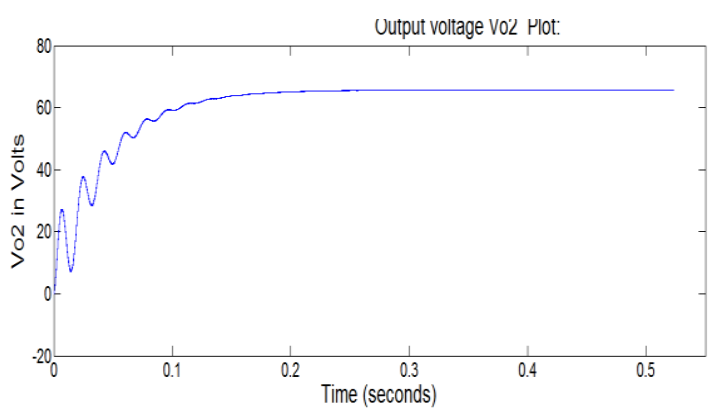

Fig.8. Output voltage $V_{o 2}$

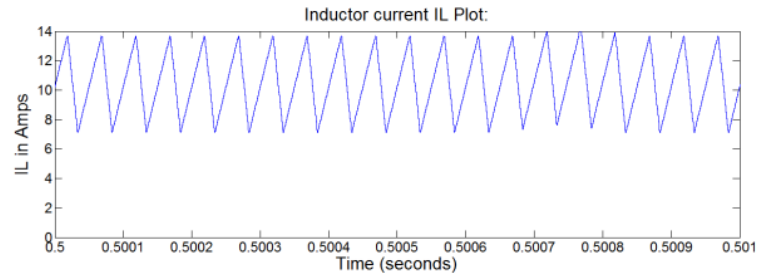

Fig.9. Inductor current $I_{L}$

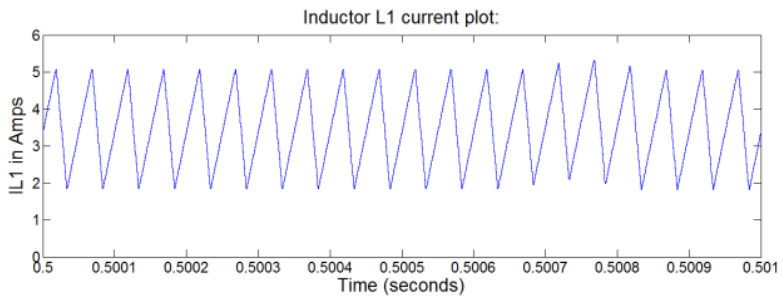

Fig.10. Inductor current $I_{L 1}$ 


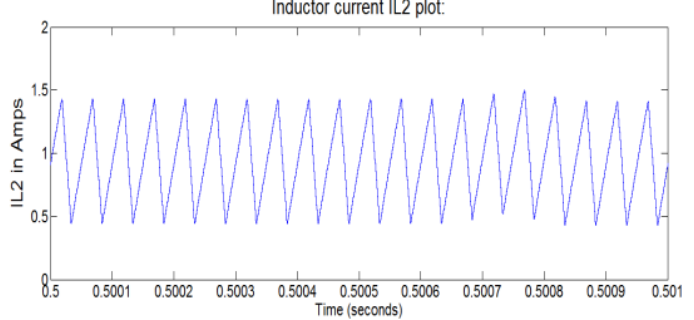

Fig.11. Inductor current $\mathrm{I}_{\mathrm{L} 2}$

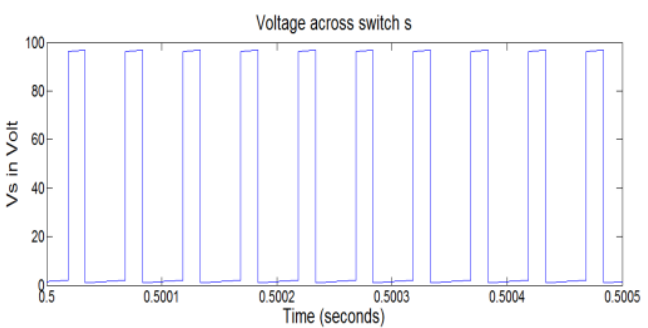

Fig.12. Voltage across switch $\mathrm{V}_{\mathrm{Sw}}$

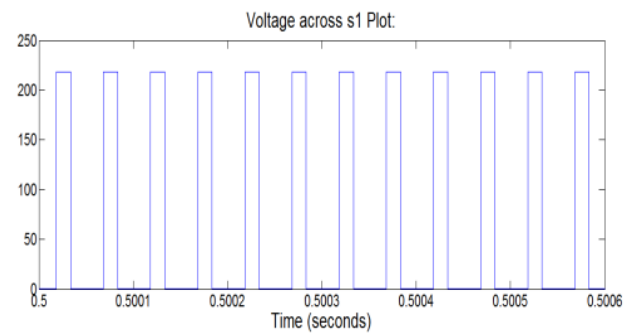

Fig.13. Voltage across switch $\mathrm{V}_{\mathrm{SW}}$

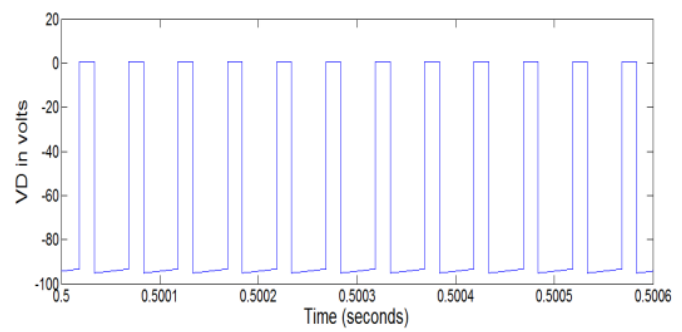

Fig.14. Voltage across Diode $V_{D}$

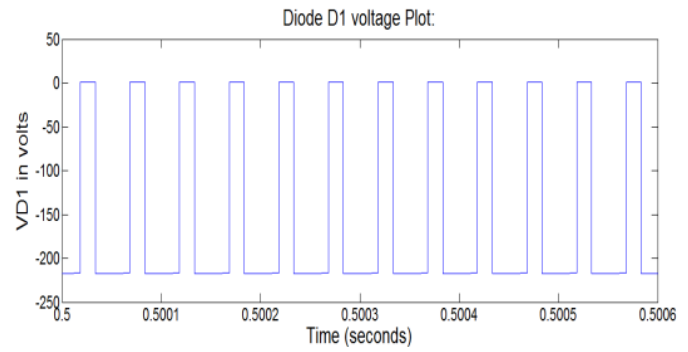

Fig.15. Voltage across Diode $\mathrm{V}_{\mathrm{D} 2}$

In order to automatically achieve and maintain the desired output condition, closed loop system is designed. The output condition is compared with the actual condition. It is done by generating an error signal which is the difference between the output and reference input. The error signal which is the difference between the input signal and the feedback signal is fed to the controller so as to reduce the system error and bring the output of the system back to the desired value as shown in Table.2. In this design, the controller used is PID controller and it is tuned by trial and error method.

Table.2. Output for various input voltages

\begin{tabular}{|c|c|c|}
\hline \multirow{2}{*}{$\mathrm{V}_{\text {IN }}$ in Volts } & \multicolumn{2}{|c|}{$\mathrm{V}_{\text {out }}$} \\
\cline { 2 - 3 } & $\mathrm{V}_{\mathrm{o} 1}$ in Volts & $\mathrm{V}_{\mathrm{o} 2}$ in Volts \\
\hline 28 & -229 & 66 \\
\hline 29 & -228 & 67 \\
\hline 30 & -230 & 68 \\
\hline 31 & -228.6 & 68.58 \\
\hline 32 & -229.4 & 69.6 \\
\hline
\end{tabular}

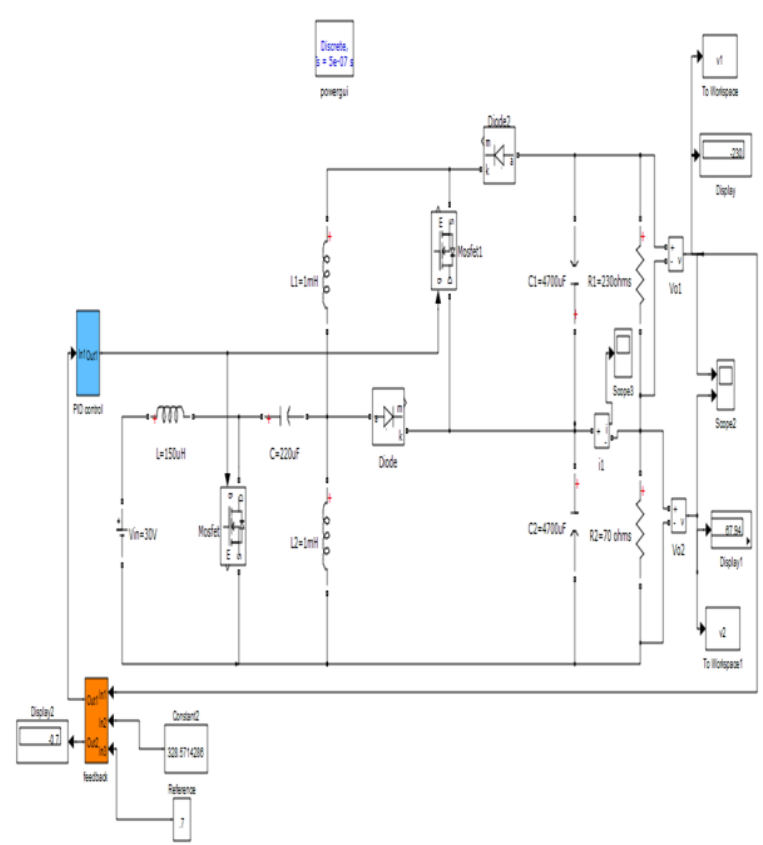

Fig.16. Simulation model of proposed converter with feedback

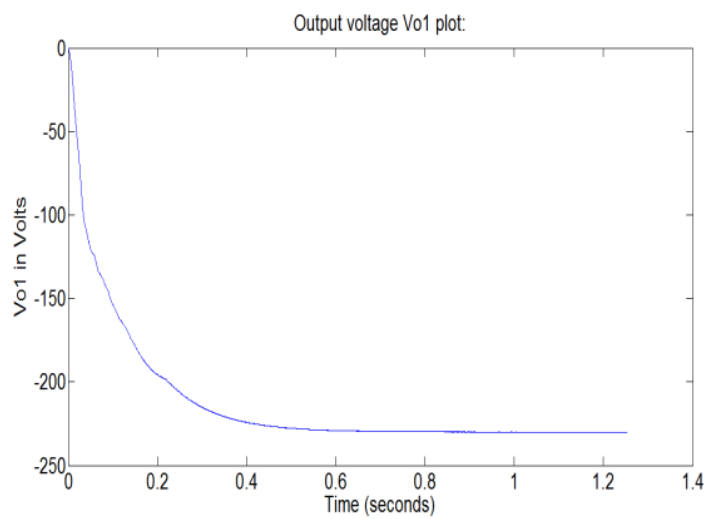

Fig. 17. Output voltage with feedback $V_{o 1}$ for $V_{I N}=30 V$ 


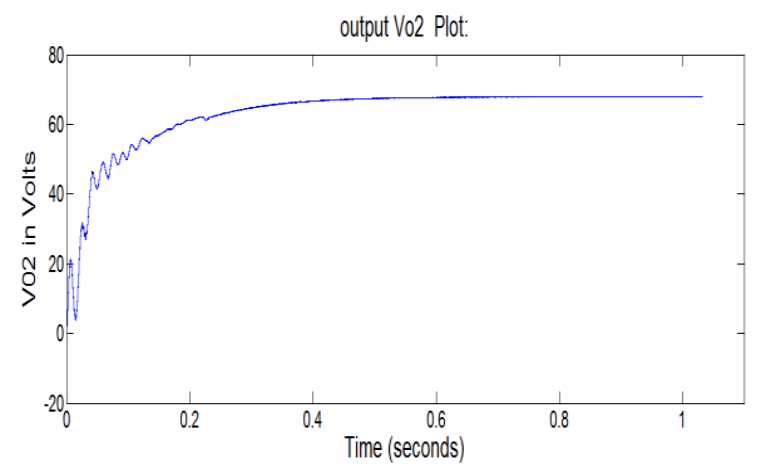

Fig.18.Output voltage with feedback $\mathrm{V}_{\mathrm{o} 2}$ for $\mathrm{V}_{\mathrm{IN}}=30 \mathrm{~V}$

\section{CONCLUSION}

A Dual output converter has introduced by combining conventional CUK and SEPIC converter. Steady state analysis of the proposed converter is carried out completely. Open loop and closed loop simulation are done using MATLAB/SIMULINK tool. From the simulation, it is verified that the both the output remains approximately constant even for $\pm 10 \%$ variation in input voltage.

\section{ACKNOWLEDGMENT}

I express my gratitude to Visvesvaraya Technological University, Belagavi for providing me an opportunity. I extend my sincere thanks to our esteemed institution NMAM Institute of Technology, Nitte for supporting me in all the ways possible.

\section{REFERENCES}

[1] P. Klimczak and S. Munk-Nielse, "A single switch dual output nonisolated boost converter," in Applied Power Electronics Conference and Exposition, 2008. APEC 2008. Twenty-Third Annual IEEE, 2008, pp. 43-47.

[2] M. S. B. Ranjana, N. Sreeramula Reddy, and R. K. P. Kumar, "A novel SEPIC based dual output DC-DC converter for solar applications," in Power and Energy Systems Conference: Towards Sustainable Energy, 2014, 2014, pp. 1-5.

[3] K. Hwu, Y. Yau, and J.-J. Shieh, "Dual-output buck boost converter with positive and negative output voltages under single positive voltage source fed," in Power Electronics Conference (IPEC), 2010 International, 2010, pp. 420-423.

[4] A. Nami, F. Zare, A. Ghosh, and F. Blaabjerg, "Multi-output DC-DC converters based on diode clamped converters configuration: topology and control strategy," IET power electronics, vol. 3, pp. 197-208, 2010.

[5] R.-L. Lin, C.-R. Pan, and K.-H. Liu, "Family of single-inductor multioutput DC-DC converters," in Power Electronics and Drive Systems, 2009. PEDS 2009. International Conference on, 2009, pp. 1216- 1221.

[6] A. A. Boora, F. Zare, and A. Ghosh, "Multi-output buck-boost converter with enhanced dynamic response to load and input voltage changes," IET power electronics, vol. 4, pp. 194-208, 2011.

[7] M. R. Banaei, H. Ardi, R. Alizadeh, and A. Farakhor, "Non-isolated multi-input-single-output DC/DC converter for photovoltaic power generation systems," IET Power Electronics, vol. 7, pp. 2806- 2816, 2014 .
[8] M. Zhu and F. Luo, "Series SEPIC implementing voltage-lift technique for DC-DC power conversion," Power Electronics, IET, vol. 1, pp. 109-121, 2008

\section{BIOGRAPHIES}

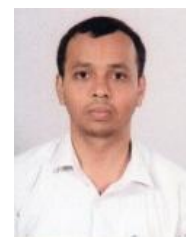

Shankara Pai B received his B.E (E\&E) degree from, St Joseph Engineering College, Vamanjoor, Manglore, India in 2007. He is pursuing his M.Tech (Power Electronics) in Nitte Mahalinga Adyanthaya Memorial Institute of Technology, Nitte, Karkala, India. His area of interest includes Renewable energy research, Power Electronic and Power System technology.

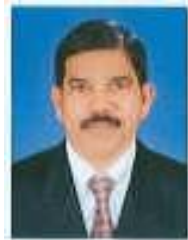

K. Vasudeva Shettigar received his B.E. (E \& E) degree from SJCE, Mysore University, Mysore, India in 1986, and M.Tech. (Power Systems) degree in 1992 from National Institute of Engineering affiliated to Mysore University. Presently Mr. Vasudeva Shettigar is serving as Associate Professor, Dept. of Electrical \& Electronics Engineering, Nitte Mahalinga Adyanthaya Memorial Institute of Technology, Nitte, Karkala, India. He is Life member of ISTE. He has published 11 technical research papers in various National and International conferences. He has chaired International conference held at NMAMIT Nitte during May 2011, 2013 and 2015. Mr. Shettigar has organized several National Conferences and National Workshops and Short term training programmes (STTP) in the college for the benefit of faculty (NMAMIT) and faculty of neighbouring Institutes. His areas of interest include power system \& protection, power quality and High Voltage Engineering. He has a teaching experience of over 27 Years, and guided over 50 U.G \& 24 P.G. Technical Project works. 